Part 4Four

Changing Minds

10

\title{
Reflections on The Eradication of Schizophrenia in Western Lapland: A eConversation between David Woods and Jon Haynes of Ridiculusmus with commentary by Richard
}

\section{Talbot}

\section{Introduction}

JON: Going up to people going 'Oohhhh! Margaret! Ooh!' In our pyjamas. that was mad acting.

DAVID: Yeah, and it was good fun.

As theatre makers who did not so much 'emerge' but rather 'burst out', this frank reflection is typical of Ridiculusmus's sense of comical mischief. Nevertheless, a series of recent productions have demonstrated a serious preoccupation with the problematics of representing mental illness on stage. Artistic Ddirectors David Woods and Jon Haynes ${ }^{1}$ have become increasingly involved in discourses around medical provision for mental ill health and the impact on individuals and families. Ridiculusmus have also worked with academics at the cutting edge of research into clinical therapies and invited them to post-show discussions and other public engagement activities. Consequently ${ }_{2}$ their work has made an important contribution to the public awareness of the latest approaches available to mental illness diagnosis and treatment.

In the following dialogue initiated by Phéline Thierens, ${ }^{2}$ David and Jon trace their experiments with 'performing psychologies', from childhood to early performances as the Ridiculusmus ensemble, and finally in their most recent work, in which they claim to have rejected both 'mad acting' and acting 'mad'. The most recent work comprises a trilogy of performances with the consistent objective of combining research insights with innovations 
in approaches to audience engagement. Like many twenty-first--century contemporary theatre makers, Ridiculusmus have grappled with the transition from a postmodern aesthetic and interest in contingency to a direct and politiciszed concern for issues relating to mental ill health as they are experienced. Although supported by funders who hope to increase awareness of the benefits of recent biomedical research, the work is not about mental healthcare development in an illustrative sense; rather, it is inclined to explore the boundaries of theatrical representation and comic play, and the process pushes at the limits of public discourse around madness.

What follows is a collection of eight short sections of dialogue taken from a longer reflection on the company's creative process, predominantly focussing on the making and touring of The Eradication of Schizophrenia in Western Lapland (2014). The sections have been selected because they highlight inclinations emerging in the company's recent practice.

\section{Staging pPsychosis}

Eradication is a production with four performers in which the playing area and audience is

Comment [Q1]: AU: For consistency, we've removed the head level numbers throughout this chapter. Please confirm.

divided. It would be a mistake to assume that this set design is a straightforward instantiation of R. D. Laing's psychiatric concept of 'the divided self', as David and Jon are very clear that they are not representing split personality as a definition of madness. Rather, the divided space has multiple effects: of allowing a synchronicity of text and gesture, and of allowing characters apparently to be in touch with the drama happening across the divide. Actors move between the two spaces, and so can shift quickly from one time-space to another. Added to this sculptural device of a divided space, the movement of time on each side operates differently: one is moving forwards in time, the other backwards through a number of key moments. After an interval, the audience switch sides and are able to see characters and scenes that in the first half only appeared as shadows at windows or as fleeting interjections into the more continuous scene immediately in front of them. After the interval some 
audience members experience more clarity because what appeared distant and inaccessible is now visible and clearly audible. However, the action and delivery of lines is speeded up considerably and the play ends with all the characters dancing in both spaces, so that the separation of 'here' and 'there', inside and out, becomes almost redundant.

The two spaces are a doctor's consulting room; and a family room. Richard is undergoing a talking therapy with a doctor who is having his own family crisis and who frequently takes mobile phone calls during which he attempts to defend his style of parenting. On the 'family side', or 'private side', 'Mum' is with Rupert, Richard's younger brother, and they are waiting for the father to come home. At one point the doctor leaves the clinic and appears at the family's door, weaving these two stories and spaces together. Richard also moves between the clinic and the home, initially carrying a knife. Mum paces the domestic space, while her youngest son Rupert alternates between disengagement and caregiving, sometimes criticiszing his older brother for leaving him to do this alone. Rupert expresses the burden of a young carer through fantasies about the house being haunted, picking up on his mother's ramblings about Dracula. The physical action is contained, choreographically geometric and minimal. Much of the text on the family side sounds like a mantra reflecting household banalities such as tidying and planning meals (that never appear). Mum and Rupert rehearse the problem of how to manage Richard, who is now home from university. While he was away Mum reorganiszed his room, setting up a space for her yoga practice, and Richard resents it. Richard has started a relationship with a transgender person, much to adolescent Rupert's amusement. While Richard was at university Mum had a psychotic episode and Rupert signed papers that approved her being sectioned, briefly. Richard is critical of this. Throughout these events the father is absent, at work or having an affair. As these facts emerge the family seems caught in the centrifugal forces of mashed codes apparently generated by Richard. Richard is writing a play, and he tells his therapist, 'we're in it now'. 
Lines are overheard and echoed by all the characters, becoming misplaced in conversations 'on the other side' where they trigger new meanings and confusion.

JON: The play we started making was originally going to be a family drama. It was a reaction against us doing lots of shows featuring two people, either two strangers meeting or two people at work. We began to crave characters that might have a deeper connection with one another, as in a family.

DAVID: We 'mined' our family stories, for the big things. My dad's breakdown, my brother being sectioned, your mother's death__ _ all this kind of stuff - and they became the stories. We started by making a quite conventional drama, with mental health content and it was really very, very boring. Then, at some point, I don't know when exactly, we decided to make two scripts run at the same time. That was the moment when it became a Ridiculusmus project again, really, rather than just us trying to do a straight, kind of normal theatre show. God knows. I mean it comes from various other influences.

JON: You mean for the staging?

DAVID: Yes, but they weren't all exactly the same as this idea. This was influenced by a French show that I'd heard about where they had the kitchen of a restaurant and the restaurant,, and Two-Faced Bastard, a dance-theatre show by Chunky Move (Malthouse Theatre, Melbourne, 2008). ${ }^{4}$ It had an audience watching either side but no synchroniszed double text, and Michael Frayn's play Noises Off (1982), ${ }^{5}$ which had synchroniszed prerecorded text and action but only one audience.

JON: There are also two other shows that were an influence: Ursus \& Nadeschkin-_ Solo! (1999) by the Swiss cabaret duo Ursus und Nadeschkin $-\frac{6}{-}$ and Dance Bear Dance (Arch 12a, 2003) by the collective Shunt. ${ }^{7}$

DAVID: Yes.
Comment [Q2]: AU: The dialogue in each section seems to be part of the main text. Would you prefer to differentiate this from the main text or retain as is? Please suggest your preference.
Comment [Q3]: AU: Would you allow these spelling changes in the dialogue? 
JON: I remember you had this idea or just a wish to do something in a public space. We were thinking about a railway station platform or waiting rooms, this kind of thing. Do you remember when we were devising at Metal in Edge Hill, we had that wall we made within the space, and we weren't thinking about simultaneous scenes then. We were just thinking about a room behind a wall, then another space in front of it where there were people. We didn't actually have simultaneous scenes, I don't think. It was more exploring this idea of another space.

DAVID: What happens when a private place is in close proximity to a public place.

JON: In fact, during the development phase of Eradication we used to call the family side 'the private' side and the doctor's consulting room 'the public'. Do you remember?

DAVID: But I got a feeling that was all towards trying to find a version of the double staging that worked for us. I loved this idea of this dual interpretation of a situation. That there was a whole other story behind a sequence of events.

JON: Mischa Twitchin" ${ }^{8}$ said 'Why don't you do it in a Chinese takeaway? Why does it have to be a railway station?' He said we seemed quite fixated on this railway station.

DAVID: To the point where we did a residency in a railway station in Liverpool.

JON: Yes, Metal in Edge Hill.

DAVID: This Edge Hill station was quite good because it felt like it was stranded. Later, Patrizia found a film where a train stops at an abandoned station and a very glamorous woman dreamt she got off. ${ }^{-}$What was coming together with Eradication was this feeling that this could be an articulation of psychosis. We were very wary of saying, 'Well, it's the split personality and therefore it's a split staging.'

JON: [...] It was about the auditory and visual hallucinations that were possible because the text of the scene on the other side of a wall is audible while you're watching the 
one in front of you and listening to it___ but you kept hearing this stuff. Though I'm not sure we ever thought of that while we were making it. I think this is retrospectively implied.

DAVID: There were so many phases in making it because it went over two or three years, this process. By the time of sitting in that Birmingham Hotel, mathematically working out how the text would segue into each other. It was definitely making that. It was definitely to achieve this thing of two sequences of dialogue that could be heard and sort of make sense at the same time sometimes.

[...] It became very technical in the end but, prior to that, we had all the material, really. We had all the elements to make, which was this family drama stuff.

JON: We never thought, 'Oh, this would be a great way of representing psychosis.' I remember just thinking, 'Oh, this would be a really nice effect if words coincide what the people are saying.'

DAVID: My idea was that, with psychosis, you hear something and then it starts off a train of thought, which is not related to the actual conversation you're in. That's something everybody has experienced, where you start thinking about something else after you've said something and you go, 'Oh, familiar train of thought.' You might be following something on your computer and you wonder where five hours have gone, and how on earth do you spend five hours in a room with two other people apparently having a conversation about something else. Sometimes it would come back in, and a psychotic outburst is not that dissimilar to those wanderings of thought. It's just they come with usually a lot of stress and paranoia and so on.

JON: I was reading about the Hearing Voices Network ${ }^{10}$ and they just say, 'Well, you know, in some cultures, when you hear that distant, other voice, it's the voice of God and it's to be celebrated,' and then you're not labelled a schizophrenic. You're revered as somebody in connection with the gods. There's no way they would give you anti-psychotics to stop that 
voice because they want to hear that voice, so that it could be considered healthy. Whereas we consider it unhealthy. Therefore, medicate for it and then that person becomes ill because that confuses that process, which is a sort of natural response to unnatural circumstances.

DAVID: We can all start hearing voices anytime. We often do. In semi-consciousness we hear things being said, or we hear voices from other rooms. People who've been bereaved hear their loved ones.

\section{Performing M- $\underline{\text { madness }}$}

As part of the research for the project, David and Jon investigated Open Dialogue, a remarkably successful therapy that- since 1985 has reduced the diagnosis of schizophrenia in Finland by $85 \%$ per cent. ${ }^{11}$ The principles of this therapeutic method, including 'tolerating uncertainty' and a 'polyphony of voices', form part of the ethical framework guiding the devising and dramaturgy of The Eradication of Schizophrenia in Western Lapland. David and

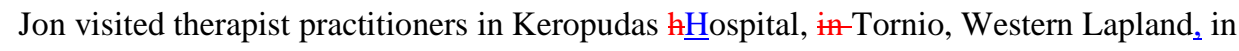
March 2013 as part of their research and once again with other performers in June 2013. The company attended a conference, The Newest Dialogical Ideas Aand Practices fin Collaboration Wwith Families Aand Social Networks, in Hämeenlinna, Finland, convened by

Peter Rober, Jaakko Seikkula and the late John Shotter. Seikkula is the primary exponent of the Open Dialogue method in Finland. This dialogic and complementary therapy treats psychosis as a condition that can be eradicated through collective and dialogic interpretation based on affective sensitivity. Therapeutic dialogue does not assert a singular interpretation of a person's psychotic manifestations, but understands it as a process of meaning-making. This method of de-stigmatiszing schizophrenia circumvents easy pathology and is now being promoted in the NHS in the UK. Influenced by the experience of performing extracts of the family drama, as a case study, and appearing in role as clients for therapists attending the conference, Ridiculusmus became convinced of the benefits of dialogic methods and 
discourse as an alternative to 'authoritative' research-led theatre-making in which issues and information dominates dramaturgy. The language and tone of Open Dialogue, and in particular, the notion of embracing and trusting 'unknowns', seemed to define a new space for mutual collaboration between clinical psychologists and theatre makers and audiences. The extent to which the project would be able to communicate or disseminate key ideas in psychotherapy or satisfy the creative development of Ridiculusmus hinged on a commitment to unknown outcomes and investment in a new understanding of their own practices. In this way $_{2}$ Open Dialogue was practiesed between 'expert-practitioners', that is, artists and the therapists, and their various audiences, such as conference delegates, theatre-goers- and clients of mental health systems.

JON: When I'm going through stressful periods I often find myself walking down the streets, talking to myself very animatedly and imagining somebody else's response and answering questions. 'Do you ever do that?' 'No, I'm not. This is ...' and then I think, 'Oh, my God. I've gone completely mad.'

DAVID: Did I tell you about my game 'Mad Man Or Mobile'?

JON: Where you pretend you're mad?

DAVID: No, I look at people who are walking around the street like you, talking to themselves, and I have to guess if they're mad or on their mobile with an earpiece - you check the other side of their ear to see if there's a Bluetooth or not, and if they're not wearing one, they're mad.

JON: How do you know they're mad?

DAVID: Well, that's the label. It's considered socially abnormal so therefore it's mad.

JON: People do look very worried when they see you talking to yourself. Surely that should be a good thing. 
DAVID: It's considered to be dangerous because if you're doing that, which is not socially acceptable, what else might you do? You've maybe got the knife in the pocket etc.

JON: Yes, people have caught me doing it. 'Oh, shit. There's somebody behind me.' Then I take my phone out, but it makes no sense. Why would you be talking and then suddenly pull your phone out?

DAVID: Because you're on Bluetooth and it cut out.

JON: Or I start doing lines of text that are obviously me doing Shakespeare.

DAVID: This is what we were learning with Open Dialogue, that monological pursuits are not healthy if you really want to build a society, build communities together, you have to be in dialogue with each other. So the challenge with Open Dialogue was to engage the person [stuck] in the monologue into a dialogue, and then find out what really was the trauma behind this sane response to an insane circumstance.

JON: In the Wellcome Trust interview I said how much I liked the 'tolerance of uncertainty' principle of Open Dialogue $\frac{12}{12}$ and then Professor Peter Kinderman said 'I really

like "polyphony of voices"'. Then he talked for about twenty minutes, non-stop. 'That's not polyphony of voices,', I said. 'You've now become completely monological.'

DAVID: You said that?

JON: I did. It was kind of funny. Sorry about the interruption.

DAVID: No, that's great. I think that this is good as well because this is polyphony and we're arriving together at a kind of shared understanding of where Eradication came from.

\section{More Ththoughts on Pperforming Mmadness and our Aapproach to Iit}

For Adam Phillips, writing in Threepenny Review, acting madness involves impersonating someone who is literally trying to keep up appearances, because one fear behind losing one's mind is the fear of becoming lost to others' minds, of disappearing, socially. $\frac{13}{}$ Perhaps this 
explains the attention-seeking early efforts by David and Jon at performing mad: they were being extremely theatrical in a public place and thus inadvertently calling attention to a fundamental aspect of madness - _ the need to be visible. '[T]he actor acting madness [...] has to learn to appear to be mad___ but to be mad in a way that holds people's attention: that is, mad in a way that most mad people can never be' $\underline{14}$ and this is the dilemma for the performer. From an early catapulting and exuberant madness to an unnerving and internaliszed dizziness, performance of delusion can be enjoyable. Ridiculusmus do not run workshops as a 'way into' their work, preferring instead to use such contact with a potential audience to continue to devise and explore ideas. This has been the case since their residency at the Derry Playhouse from 1995 to 1999. During workshops with guest performers, for example, the intermingling of expansive devising and facilitation proved baffling for some.

Direct experience of the impact of the Troubles in Northern Ireland on spontaneous expression contributed to Say Nothing (1999), a show performed entirely on a tiny patch of turf squished into a suitcase.

During devising sessions for Eradication at Edge Hill railway station, the company created the role of a social worker who comes to support someone who is 'going mad' but cannot determine which member of the family it is, because they all appear to be acting strangely; as Phillips says, madness is theatrical. The way in which signs of madness are distributed amongst the social circle of individuals directly gripped by mental ill health is recogniszed in Open Dialogue therapy, and so a community is called on to acknowledge the affective and collective performance of madness.

In the play, the literary parallel of theatricality is found in the boundary between egotistical hyperbole and popular mythology. Richard's laughable claims around the Nobel Peace Prize committee and cryogenics are based on actual instabilities in reality - the committee procedure is secret and not revealed to the general public and cryogenics is 
sufficiently speculative to offer a hint of plausibility. The madness retains the slightest grip on present reality. The same could be said for a story told by Mum about the origin of the Dracula narrative. Both fantasies speak to the idea that there may [be] some truth in his madness.

DAVID: Could you give a statement on what you think our approach to mad acting, or what our thoughts on performing madness are?

JON: If you go back to Yes, Yes, Yes (Edinburgh Fringe, 1999), $\underline{15}$ well, actually, all the way back to 1997 when we were running around in the Botanical Gardens in Belfast pretending to be Geoffrey Rush.

DAVID: In the film Shine (1996).

JON: Going up to people going 'Oohhhh! Oohhhh! Margaret! Ooh!' In our pyjamas. Well, that was mad acting.

DAVID: Yeah, and it was good fun.

JON: There was also ... I don't know if this is mad acting, but a Derry devising session where we were running around with a couple of boxes on our heads.

DAVID: Which were stuffed full of clothing, and we were sort of burying our heads in them, and then sliding around the floor.

JON: Scaring the participants.

DAVID: They said it was 'disempowering-'.

JON: So in those days, we were embracing almost stereotypical representations of madness, and these days our good taste doesn't allow us to do that. There's an Adam Phillips essay about acting madness ${ }^{16}$ where he actually talks about Geoffrey Rush playing Diary of a Madman on Broadway, saying, you know, it's very compelling viewing, but this isn't really madness, because if you put madness on the stage you wouldn't want to look at it. It's actually really horrible.
Comment [Q4]: AU: Please confirm if you approve this change. 
DAVID: But yet, people would go to Bedlam for entertainment.

JON: That's true, isn't it? But in a play, on stage, maybe it's ... If you put a mad person there would that be absolutely horrible? Maybe people have done it. I'm not sure whether we've ever talked about it, but we didn't want it to be obvious who was the mad person in the play. Which is very Open Dialogue.

DAVID: Well, basically, you never act mad at any point, do you?

JON: No, but the things my character says are not really rational thoughts, are they?

They're odd. That I've been nominated for the Nobel Prize. That Hitler is my father. Because of his frozen sperm.

DAVID: They're people telling tall stories.

JON: And if you think about the stuff the mother character says about Dracula coming from Ireland. It sounds mad but it's actually true.

DAVID: But taken out of context, it comes across as madness, and normalizing 'madness' fits with our saying, 'It's not that dissimilar to what you might feel on a daily basis.'

\section{Losing $\theta \underline{o n e s e l f}$ in Tthe 'Fflow' and Córeating Ppsychosis}

Collaborating as long-term creative partners, David and Jon benefit from a heightened sensitivity to one another that extends to the use of space and, as they suggest, to the atmosphere generated in the rehearsal space. An intoxicating mode of interaction in which performers have developed sufficient trust to 'let go' may be likened to a level of perception called 'flow'. Flow implies a reduction of self-consciousness to the level of a useful but nonintrusive awareness that a performance is unfolding. The condition of total preoccupation and immersed investment in the here and now is a kind of suspension somewhere between energiszed relaxation and concentration. ${ }^{17}$ For David, flow begins with an idea about becoming immersed in character. Jon extends his awareness of flow to include the 
performance environment. A productive atmosphere requires not only an internal sense by the performer of maximum individual investment in devising; but an awareness of its effects. Thus identification with extracts of text from previous rehearsals, are assembled along with significant gestural phrases, and these draw other performers into conjectures that lead to a shared immersed creativity.

Jon and David appear to be exploring the limits of other people's tolerance of an ideaand using interaction with others to go beyond what one is able to conceptualisze alone.

'Mad' people have been associated with a kind of privileged voice, and afforded a licensce to perform alterity; and to bring a fresh perspective on social norms. At Keropudas Hospital, in Tornio, Finland, the psychiatric team respond within hours of a call for help following a psychotic crisis. They visit their clients in their own homes to diffuse and reconfigure the family response to a psychotic event. The psychiatrists self-reflexively incorporate themselves in the dialogue around a psychosis, openly discussing their own feelings as witnesses of the atmosphere in the family group. They regard everybody within a family or community structure as having some agency within the after-affect of a psychotic event.

DAVID: Then we've come, now, to this point where we're making Schizophrenia, improvising and trying to get lost in character, aren't we? That's a good improvisation, when we lose ourselves in the flow of something.

JON: Not necessarily character, but something ...

DAVID: Performance tension or something.

JON: Atmosphere.

DAVID: Can you think of moments like that in rehearsals, where you thought, 'Yes, we're onto something here!'

JON: In Eradication? No, I can't.

DAVID: At Felsted School went off on that rant about Hitler's sperm. 
JON: Oh, yeah.

DAVID: That was the best.

JON: I do remember.

DAVID: That was the best thing in those two weeks.

JON: I remember Johnny Boy's $\frac{18}{}$ comment was 'I want what you're taking.'

DAVID: Which is often what people say to us when our shows are going well, isn't it? 'I don't know what they're on, but I want some of it', because it's some kind of magical transformation. You know, you hit a flow. Thinking of that moment, what was it you were tapping? What was happening?

JON: I have no idea. Sorry, that's not very useful, but I don't know. I mean, I suppose I'd been reading stuff, hadn't I? I'd been watching a lot of videos of Will Self. I have actually no idea why I had. Maybe I just found him interesting: this very confident, highly articulate person. And then I was thinking about my childhood and how in school I had told that story, to a boy, when I was 10 or 11, that Hitler was actually my father.

DAVID: Why do you think you did that, as a boy?

JON: To be more interesting than I was. I did that a lot.

DAVID: My son told his swimming teacher that I was dead

JON: On several occasions, I told somebody very seriously (and people believed me), that I was building a spaceship in my shed, and I was going to go to Jupiter. I'd discovered this chemical that you could paint on things so that they'd lose gravity. Just, taken from The First Men in the Moon by H. G. Wells. A friend of mine agreed that he'd come with me.

DAVID: There is a trait there, which is shared with people who are labelled 'mad'. An insecurity. You wanted to defend yourself, or make yourself more interesting, divert people from your boring reality, by saying, 'Oh, I'm this', so they'd be attracted to you. It's sort of a self-esteem problem, or non-problem. It's just a condition that we feel at times. 
JON: Maybe it wasn't. Maybe it was more selfish. I wanted to feel more interesting myself, not for other people to be more interested in me. Or maybe it's a bit of both.

DAVID: Why do we do anything really? It's sort of to entertain ourselves, isn't it? If you entertain yourself in a way that also entertains others, you become popular, and then you're winning on two fronts, aren't you?

JON: Or maybe it's kind of playing a game and then drawing other people into the game, like the guy who wanted to go with me to Jupiter. These people, maybe they knew it was rubbish, but they wanted to go along with it.

DAVID: So, you were tapping into this childhood memory, and research, let's say, about Will Self, because, had we already decided he was a writer? I seem to remember you going on about Margaret Drabble at Warwick Arts Centre.

JON: I don't remember.

DAVID: Then, later, I think in preparation for the Finland trip, we were discussing what our backstory would be, to see if these guys could work it out, and we agreed, through discussion, that your writer character was delusional about being an amazing writer, because it was the only moment of connection he had had with his father-_ 'That's really good writing, you might be a writer one day!' or something like that. Somehow, in the meltdown of your stressed-out mind, of leaving home, Mum going to hospital, and your world falling apart, you'd clung on to this idea that you were this great writer, and therefore Dad would be proud of you, and then, maybe Mum would come back. It was that kind of sequence of thinking.

JON: I remember that when we went to Tornio, to the hospital.

DAVID: Keropudas Psychiatric hospital in Tornio. I thought in the improvisation there we were two artists on a retreat in Finland, and we got a blocked chimney, and I was really obsessed, and then later, Timo Haaraniemi said, 'Oh, where are you staying?' At the 
end of our visit, we'd done the improvisation, and he said 'Where are you staying?' We said, 'Oh, we're in this hotel here. It's really hot and stuffy', and he said 'Ah, a blocked chimney!' JON: The real hotel, you mean.

DAVID: He was playing detective with us.

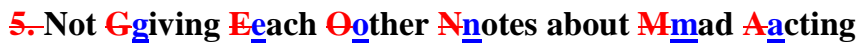

Self-consciousness may stall an actor when they become too aware of the external expectations of an audience, or more specifically, a director. Unless they understand their function as a co-author, this may be challenging for a director. Due to production timescales, the published script of Ridiculusmus' $\underline{s}$ work is often not the script as it is heard on tour; but an early version. David and Jon assert their authorship here, but in almost every other respect they take a pluralistic approach to generating and determining the script. They resist directing individual actors, concentrating instead on questions of the pace, rhythm or 'scale' of expression by the whole ensemble. They frequently substitute actors in parts that they have created for themselves, or swap roles between themselves. ${ }^{19}$ David and Jon seem less concerned with questions about the 'ownership' of a piece of text by an individual contributor or performer. Indeed, what they appear to be looking for in their collaborators is an ability to relinquish a text.

The process of writing the script involves open-ended conversations with diverse collaborators. Improvisation then revisits interactions and fragments of conversation, and this is recorded. Transcriptions of these recordings are performed then combined with other 'bits', re-ordered ${ }_{2}$ performed and learned. A fictional narrative with an appearance of veracity emerges. Where narrative elements are missing, David and Jon resist the temptation to script autonomously, but return to an earlier phase in the process, proposing new situations for improvisation until a 'whole' script evolves. This is tested in public performance and edited assiduously throughout the early touring versions of the production. 
The written text retains the ornamentation littered around improvised expressions or ideas. Given these post-structuralist inclinations, it may not be surprising then that Ridiculusmus are less interested in psychological significance, subtext and gesture, that is, the currency of some directors' negotiations with actors. Rather, they are preoccupied with the tempo and duration of scenes, the musicality of repetition, and of rhythm in the whole text. Critical decisions about what works in the context of such preoccupations continue to develop even while the material is performed to the public.

JON: The other thing I was thinking is that we never really give each other notes about our acting.

DAVID: No.

JON: Which is what a director does, and I've realized really irritates me, and I always give a worse performance when I'm given notes. Because I've been told to do something, because I've got to think 'Oh, now I've got to show that', this thing, and then therefore I can't really get lost in it. You've got to get their approval by doing this thing that they want you to do.

DAVID: We've come to an understanding that if we want flow, we mustn't give notes.

JON: But we never said, 'Okay, you're playing that too mad. You're not playing that mad enough.' Or at least, I don't think we did.

DAVID: I suppose we give notes indirectly in the editing. In a way, the inclusion or exclusion of material says, 'This is the kind of thing that will fit with my idea of what this play is', and we come to a kind of harmonious agreement of what those bits are, that then stick together into the play.

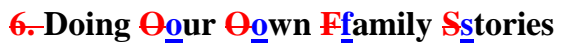

DAVID: I know of one moment for me, when I felt I was in flow, recreating my dad at the 
window of the National Theatre Studio. Do you remember that?

JON: I do.

DAVID: I was like some sort of strange, nervous bird, 'There's a car coming, there's not a car coming $\overline{-}_{2}$, and all this kind of thing, and I couldn't see anything out that window, but I was right back in 1983, and witnessing my dad's first nervous breakdown, and not understanding it, the strange, cyclical talk of the chronically anxious, and finding it really therapeutic, but also that it is totally overwhelming me as a performer. I was loving it, just totally lost in it. Feeling like, even though my back was to the room, and I was looking out the window, that I was performing something of interest that could hold an audience's attention.- Because it was having such an effect on the other characters. It felt like a very strong thing, and it was memory, it was therapeutic, but it was chronic anxiety. It wasn't psychosis.

JON: But yet, when you take anxiety to such an extreme, that it becomes delusional, then you really are in the realm of schizophrenia.

DAVID: Yeah, but these are the headline-grabbers. It's this minimal thing. Again, we wanted to, I suppose, because of the influence of all that, say, 'If you start worrying, that's step one towards what is labelled "schizophrenia.", You can choose this or that label and step-by-step, you could end up at the point where you're stabbing yourself and your family with a carving knife. That carving knife in the show was to say, 'We acknowledge that carving knives are associated with madness.' But we wanted to subvert that. Your first appearance is with the knife, isn't it?

JON: Yes, like, 'I'm cooking pasta. I can cook pasta.'

DAVID: And then you come through to the doctor's side, and I see you with the knife, and I take it off you. 


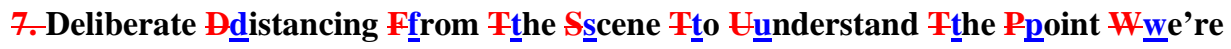 Mmaking}

Metatheatre, or metatheatricality, is a dramaturgical style that appears frequently in

Ridiculsumus's work, as it does in so much contemporary and postmodern performance.

Conventionally ${ }_{2}$ this is a device such as the 'play within a play', by which the formal structures of the play are acknowledged in the style of playing. Noises Off, a famously self-

referential farce, was discussed during the devising of Eradication. Here, however, the inclination towards self-reference does not elucidate the genre- or present anything so straightforward as a play within a play. Although it is structured and conducted with the formality and constraint of a chamber piece, Eradication is replete with sensory interruptions and visual disturbance that repeatedly draw attention to moments of coincidence, dissonance and synthesis. With a central character claiming to have composed reality, the play suggests that reality is a matter of contingency, creativity and imagination. The discipline required by the actors to memorisze an interlocking four way spoken text. For audiences this might privilege the rehearsal required for this work to be effective. Moments of clarity seem to 'land' when there is singular coincidence of phrases and meaning. When the text falters or appears to disconnects $s_{2}$ however, the audience is reminded of contingency and adaptation in live performance. The staging enables the audience to hear part of the text twice. The set places the audience in two different spaces and they become aware of the different experience of the play that each group has. The split audiences can hear each other and thus perform for one another, actutely aware of another group watching, listening, witnessing. Selfconsciousness or double consciousness, then, is not only the reserve of the performer on stage. Here the audience as groups of people set apart from one another become conscious of what others are hearing, the condition of a hyper-sensitive person in everyday society. At times the audience see some action through net curtains and as shadows on the curtains. 
Plato's metaphor for human consciousness and representation is a cave wall upon which are cast the shadows of people who are chained in front of a fire. This is an appropriate model here as the audience allocated to one side of the performance space are aware of both the present action and that which takes place in another room. The two spaces are, respectively, the family home of Rupert, Richard and their mother, and the clinical psychiatrist's treatment room (or vice-_versa depending on the order that you experience these). The audience members see a world enacted in front of them, but the usual sense of engagement in that world is held at a distance. Just as in dreams, figures can appear to shift their guise without breaking the undertow of their intentions, so the characters in the two different scenes are also simultaneous. This duality is also experienced in some psychotic delusion. This device can disrupt the dramatic narrative performed in the spare and simple staging in front of each group. A simpley family scene is distorted and the relations between characters and scenes are not always transparent. There is a very clear logic for David and Jon as writers. Not only are the dialogues from the two scenes interlaced, the scenes on each side are also moving backwards in time. When the audiences swap over in order to watch the scene on the other side, what they see is a truncated, speeded up version of what they have already overheard. And yet, because they have the memory of what previously were intrusive phrases, there may be a greater sense of clarity in repetition. Richard describes the play he is in as a reality created by himself and consequently the reality of others is subject to the whim of his creative writing. The tactic here seeks to avoid pinning down any certainty about the location of 'madness' and what is reality, and this is a much more complex device than an effect of 'alienation' discussed now.

DAVID: What about where we deliberately distance, so that people, in a Brechtian way, are able to detach themselves from the emotions of the scene, in order to understand the point that we're making. What about that? 
JON: Can you think of an example?

DAVID: Where we deliberately break the fiction. The fourth wall, although it's a bit confusing in that context, because we've got two sides.

JON: You mean like meta-theatre?

DAVID: That kind of thing.

JON: The bit about the name of the play we're in. Is that what you were thinking?

DAVID: Yes, that.

JON: That's not really alienation, is it? We're still lost in it.

DAVID: Because we don't do it, do we? Metatheatre, for us, only reveals another layer of fiction. We reinforce the inner layer of fiction by revealing a second layer of fiction, rather than reality. We're trying to find a second layer that supports that inner layer of fiction.

\section{No Ffourth Wwall and David Ggoing Mㅆmad}

Eradication opens with a longeur. The psychiatrist looks out to the members of the audience in anticipation, of a response, as it turns out. His first line, 'You seem very quiet today', sets the tone for a reflexivity that will incorporate the audience. This presents the audience with uncertainty, a risky tactic at the outset of a play. When language fails he draws a diagram of psychosis locating himself in relation to the reality of his patient. He addresses the audience as if they were his patients; and directly provokes questions about how they perceive one another. Partly due to its stubborn, yet ridiculous, complexity ${ }_{2}$ the diagram is laughable. The comical impossibility of diagrammatic representation and of a clear clinical presentation, as David describes it, is are complicated by the pace of the scene on the other side of the wall. To synchronisze with the other scene as an actor David has to introduce moments of hiatus, during which the audience may feel that a response is expected from them. David actively includes the audience 'in our fiction'; and uses a performance technique to focus his attention on people who, voluntarily or not, are momentarily distracted, looking away the moment that 
their attention returns to him, perhaps provoked by the feeling that they are being watched closely. It underlines a notion of co-presence and the responsibility for each audience member to make individual meaning from within the notion of audience or, as David calls it here, 'mob'. He is referring to the volatility of an audience at the outset of a play. For actors and audiences, the progress of a play on any particular night is unknown and the first few minutes can often set the tone. There is an implicit invitation to interact in David's glances and close 'listening'. He is inviting participation by each individual, but audience members may not have the confidence to speak out. Laughter is a more collective manifestation of interaction but David and Jon reflect on the risks of pursuing a dialogue through laughter. In the instance they mention here, sniggering in the audience grows into a hysterical uncontrolled exchange that exceeds the purpose of encouraging alertness on the part of the audience. Rather than evaporating the fourth wall, such an exchange might establish an a Formatted: Font: Not Italic priori relation between performer and audience before the fictional constructs of the doctor character and his 'clients' are introduced.

DAVID: There are other moments where I broke ... you know, when I'm doing that very difficult opening speech, of the doctor, doing his medical presentation. Because of the nature of the material, you're doing the scene on the other side, and I'm just standing there and trying to hold the moment. The only way to do it was to look at the audience. Because they were a living, unpredictable mob, if they coughed I would look at the person who was coughing, or if they were on their phone or if they were talking. The fourth wall, if anywhere, was outside the auditorium, It, includes the people in our fiction.

JON: But you'd do the same thing in Give Me Your Love, with the box $?^{20}$ You'd look Comment [Q6]: AU: Please check this part of the text. at people if they coughed.

DAVID: Yes.

JON: I remember you giving me that as a note, or something: some business to do. 
DAVID: It's a way of keeping their focus, as well, because it also recognizes the fact that the event is live, and that's one exciting possibility of theatre, that anything can happen, and it's here, and it's now.

JON: What about that moment? When we were in BAC, that night when you were doing the doctor and those two people started giggling, and then you joined in. What was going on there? Were you starting to perform their psychologies with them?

DAVID: I think I was going mad, because their laughter was making me laugh ... that mad feeling of uncontrollable laughter.

JON: You were joining in with their hysteria. Was there a moment where you were conscious of, 'This is probably helping them, this is probably a good thing to do', so you let it go on?

DAVID: No, it was uncontrollable.

JON: But afterwards, you said that, I think, didn't you?

DAVID: I couldn't help it, because it was just so intoxicating. I don't know anything like that, beyond laughter, really, that is so intoxicating that you just can't stop it. During the Edinburgh Festival, Eradication received outstanding and almost universal critical approbation from theatre specialists and general audience members across mainstream and social media. Reviews revisited the densely woven pattern of text and at times tried to unpick its carefully threaded knots. While there were those thatwho were frustrated by the complexity of the work, there was also a huge admiration for the staging and the style of performance. The play clearly worked on people's perceptions of mental health. It increased curiosity and contributed, through post--show Q\&A, and other forms of dissemination, to the ways in which members of a family can negotiate family tension as well as social provision and care. Ridiculusmus aim to encourage dialogue and empathy in order to contribute to the quiet revolution against the stigmatiszation of mental ill health. Towards the end of the 
Edinburgh Festival run Ridiculusmus were awarded the Total Theatre Award for Significant Contribution to Theatre-Making in the UK. This may be one indication of the efficacy of the production as it attempts to improve both artistic responses and public curiosity about mental ill health diagnosis and treatment.

1 I will use the first names of Jon Haynes and David Woods, because these are also used in the extracts of dialogue that follow. The play title The Eradication of Schizophrenia in Western Lapland is abbreviated to Eradication.

2 A producer-collaborator during the development of a new production that is intended for touring in 2018 .

3 A 1989 production by Les Deschiens: Lappin Chausseur directed by Macha Makeïeff and Jérôme Deschamps at Théâtre national de Chaillot, Paris. 4 Melbourne-_based contemporary dance company. Two-Faced Bastard premiered at the Malthouse Theatre, Melbourne, in 2008.

5 Noises Off is a 1982 play by the English playwright Michael Frayn. 6 Ursus \&and Nadeschkin, a Swiss cabaret duo. Ursus \& Nadeschkin___Solo! was first presented in 1999.

7 A London--based performance collective founded in 1998. Dance Bear Dance ran at Arch 12a in Bethnal Green between May 2002 and August 2003.

8 A stage designer and collaborator on other Ridiculusmus's productions.

9 Long-term collaborator and performer Patrizia Paolini suggested a film, The Pointsman (Stelling 1986), which involved an encounter on a train.

10 Hearing Voices Network is a peer-focused national organiszation, supporting voice hearers. See https://www.hearing-voices.org/. 
11 Jukka Aaltonen, Jaakko Seikkula \&and Klaus Lehtinen ${ }_{2-}{ }_{-}$The Comprehensive Open-

Dialogue Approach in Western Lapland: I. The i $\underline{i}$ ncidence of $n \underline{N}$ on-affective $\mathrm{p} \underline{P}$ sychosis and pProdromal s. States, in 'Psychosis: Psychological, Social and Integrative Approaches' Formatted: Font: (Default) Times New Volume-3, no. 3 (2011)___Issue 3, pp179_-191.

12 A dialogic approach to treating psychosis that was developed in Western Lapland in the 1980s. See Jaakke-Seikkula and Mary-Olson, 'The Open Dialogue Approach to Acute

Psychosis: Its Poeties and Micropolitics',- Family Process, 42,3 (2003): 403-418.

13 Adam Philips, 'Acting Madness: The Diary of a Madman, Macbeth, King Lear', Threepenny Review; 126 (2011), 14-17.

14 Ibid., 14.

15 Yes Yes Yes by Ridiculusmus was presented in St- Bride's 'Continental Shifts' season at the Edinburgh Fringe in 1999.

16 Phillips, 'Acting Madness', 14-17.

17 See Mihaly Csíkszentmihályi, Flow: The Psychology of Optimal Experience, (New York: Harper, 2008).

18 John Burns, collaborator, based in Northern Ireland at the time.

19 David's role as doctor, for example, has been played by Jon Haynes and by John Gorick, Rupert has been played by Jon Haynes, Richard Talbot; and Rupert Jones at the Albany, London, and by Ben Grant in Arts House, Melbourne, Australia.

20 In Give Me Your Love (2016), a war veteran, Zach, suffering with PTSD, seeks refuge in a large cardboard box. Throughout the performance, the lower legs and a pair of trainers are all that the audience can see of the performer's body. 